\title{
Isolated low follicle stimulating hormone (FSH) in infertile males - a preliminary report
}

\author{
Nader Salama ${ }^{1}$, Mohamed El-Sawy ${ }^{2}$ \\ ${ }^{1}$ Departments of Urology and Clinical Pathology, ${ }^{2}$ Alexandria Faculty of Medicine, Alexandria, Egypt.
}

\begin{abstract}
Fbjectives: High levels of follicle stimulating hormone (FSH) in infertile males received Summary a significant attention and exploration. Studies investigating the isolated deficiency of FSH in males are few, and its real prevalence is still unknown. Therefore, the objectives of the current study was to report the prevalence of isolated low FSH in infertile males and highlight their demographics and standard sperm parameters.

Methods: Records of 3335 infertile men were retrospectively checked. Patients with isolated low FSH were retrieved. FSH levels were categorized into 3 groups based on the number of affected sperm parameter (s). Study variables were also arranged into 2 groups in relation to smoking history. A control group was included to document the changes in sperm morphology.

Results: Isolated low FSH (1.146 $\pm 0.219 \mathrm{mIU} / \mathrm{mL})$ was found in 29 (0.87\%) patients. All patients showed at least one abnormal sperm parameter. The abnormal parameters were present in different combinations within the same patient but with no significant correlations with the FSH levels. The FSH levels got lower as the number of the affected sperm parameters increased although the decline was insignificant. The most frequent abnormal parameter presented was sperm morphology (86.2\%). Anomalous sperm morphology was highly and significantly demonstrated in the head; specifically in acrosome. Abnormal sperm parameters were present in both smoking and nonsmoking groups but with no significant differences in between.

Conclusions: Isolated low FSH among infertile males has a low prevalence. This may be associated with abnormality in semen parameters; particularly sperm morphology. These patients are suggested to be found as a primary entity. However, an additional work-up is highly recommended to validate this hypothesis..
\end{abstract}

KEY WORDS: Male infertility; Low FSH; Sperm parameters.

\section{INTRODUCTION}

Human follicle stimulating hormone (FSH) is a heterodimeric pituitary glycoprotein that regulates gonadal function in both male and female.

In males, FSH stimulates Sertoli cell proliferation and function. It shares with testosterone in the initiation and maintenance of spermatogenesis (1-3). Several workers reported the positive outcome of FSH therapy on sperm quality and fertilizing capability (4-7), sperm production (5, 7-10), sperm fine construction (11, 12) and enhancement in conception rate after gamete micromanipulation $(7,13,14)$. Because of these obviously significant tasks on spermatogenesis, FSH has been acknowledged as a regular laboratory test in the evaluation of the infertile male $(2,6)$.

Most reports dealing with FSH in males have focused on its high level associated with disorders of testicular structure and altered spermatogenesis, and how it can act as a predictor of retrieving sperms for subsequent in-vitro gamete micromanipulation $(15,16)$. In such situations, FSH altered level is often accompanied with changes in other requested hormones like testosterone and LH. On the contrary, studies investigating the isolated deficiency of FSH in males on clinical level are lacking. Literature review shows mostly few case reports indicating such 
unique deficiency in males (17-19). At best, isolated low FSH in men was cited at a glance on referring to a small study subgroup whose patients were extremely few, and only to reveal the beneficial effect of FSH therapy on these patients (20). Infertile females were fortunate. Their problems with isolated low FSH received better attention. There are several studies which reported this problem in females, and research was expedited to investigate polymorphism in FSH receptor (21) and FSH auto-antibodies $(22,23)$. Therefore, the prevalence of isolated low FSH in infertile males have not yet been reported. This prompted us to assess this prevalence among Egyptian infertile males, highlight their demographics and report the implication of the isolated low FSH on their standard semen parameters; with a special emphasis on sperm morphology.

\section{Patients AND methods}

\section{Study design}

This retrospective study was carried out at the Departments of Urology and Clinical Pathology, Alexandria Faculty of Medicine, Alexandria, Egypt.

Evaluation of records of 3335 consecutive men consulting for delayed pregnancy, during the period between February 2004 to May 2012, was accomplished. Patients with FSH value $\leq$ the lower limit of the normal range (1.5-12.4 $\mathrm{mIU} / \mathrm{mL})$ given by our laboratory kits were recruited. The study was approved by the Departmental Review Boards.

\section{Inclusion criteria}

These criteria defined what we meant by isolated low FSH. So, male patients with low FSH but with normal levels of testosterone (T), luteinizing hormone (LH) and prolactin (PRL) were enrolled in the study. The criteria included also absence of any clinically detectable varicocele, excess white blood cells (WBC) in semen, antibody-mediated sperm disorder or female factor. Absence of varicocele was further confirmed by scrotal duplex scanning using 7.5 MHz probe (ALOKA,SSD-1700, Dynaview II, Tokyo, Japan). The presence of abnormally elevated WBC in semen (24, 25) was confirmed using peroxidase test (26). Lack of sperm-associated antibody was indicated by mixed antiglobulin reaction (MAR) which failed to demonstrate any antisperm antibodies in semen of these patients.

\section{Hormonal assay}

Blood samples were taken for hormonal assays in the morning at 9: 00-10:00 o'clock in a heparinized syringe. Serum FSH concentrations as well as other hormones ( $\mathrm{T}, \mathrm{LH}$ and PRL) were measured using Roche Elycsys 4020 and Cobas e411 automated electrochemiluminescence systems (Roche Diagnostics $\mathrm{GmbH}$, Mannheim, Germany). The lower detection limit for FSH was 0.1 $\mathrm{mIU} / \mathrm{mL}$. FSH levels were confirmed by re-testing on 2 different occasions. The intra-assay and inter-assay coefficients of variation were $<10 \%$.

\section{Additional retrieved data}

After final recruitment of the study patients, additional data were retrieved from their files. These included socio-demographic features as age, occupation, body weight, alcohol intake and smoking habit. Retrieved data also incorporated past, drug and family histories, duration of infertility, physical examination and semen analysis results.

\section{Semen Analysis}

At least, each patient had 3 previous semen reports when he was first seen in our university clinic. All these reports denoted abnormality in one or more of sperm parameters. Then a recent semen analysis was accomplished in our facility using manual check up in 16 cases but computer assisted semen analysis (CASA) in the subsequent 13 cases. The CASA machine was Sperm Class Analyser SCA GII (Barcelona, Spain). The examination included assessment of semen volume, sperm concentration / $\mathrm{mL}$, percentage total and active (scale A-B) motility of sperm and percentage normal sperm forms. The World Health Organization (WHO) sperm criteria were used to define normal or abnormal semen parameters using WHO 1992 handbook (24) for manual assessment and WHO 1999 handbook (25) for CASA evaluation as the study patients were recruited along several years. For further study of the association between state of FSH in the current study and details of sperm morphology as assessed by CASA for 13 patients (CASA subgroup), a control group ( $\mathrm{n}=13$ ) was included.

\section{Statistics}

The raised data were analyzed using SPSS statistical software for Windows Release 20 (SPSS Inc., Chicago, USA) on a personal computer. The relationships between serum FSH and sperm parameters were quantified using the Spearman rank correlation coefficient (r). FSH levels were categorized into 3 groups based on the number of affected sperm parameter (one, two or three) which included sperm count, total motility and morphology, and comparison between the resulting 3 groups was done using Mann-Whitney test. The sperm parameters were arranged into 2 groups (normal vs abnormal), and FSH of each resulting group was included. Comparison between normal vs abnormal group per each sperm parameter was done using independent-samples $\mathrm{T}$ test. According to smoking history, patients' data including FSH levels and sperm parameters were put into 2 groups (smoking vs nonsmoking). Impact of smoking on these variables was also analyzed with independent-samples T test. The same test was also used to compare between the study patients and controls as regard detailed description of the sperm morphology. P-value $<0.05$ was considered significant.

\section{ResUlts}

\section{Patients}

Of 3335 checked files, 29 patients with isolated low FSH were recruited. This yielded a prevalence of $0.87 \%$ for this group of patients. At entry, the patients had age (30.55 $\mathrm{yr} \pm 3.85)$, weight $(76 \mathrm{~kg} \pm 15.97)$ and FSH level $(1.146 \mathrm{mIU} / \mathrm{mL} \pm 0.219)$. There was no significant correlation between patient FSH levels and ages $(r=-0.1$, 
$\mathrm{p}=0.61)$. All patients had primary infertility with a duration (3 yr \pm 2.8 ); except 3 who had secondary infertility with a duration $(5.73 \mathrm{yr} \pm 4.94)$. All study patients were white collar employees.

Their partners were (16-29) yr old for the group of primary infertility and (21-37) yr old for the group of secondary infertility. Fertility check up of the partners excluded female factor. Past and family histories were irrelevant and the patients did not receive any prior hormonal treatment or medications which might affect testicular function. Self-reported alcohol intake was nil. Thirteen patients were smokers, another 13 were nonsmokers while no data were available for 3 patients. Clinical examination showed no abnormalities. The 13 controls had comparable age ( $27.3 \mathrm{y} \pm 3.1$ vs $30 \mathrm{y} \pm 2.8$ ) to that of the CASA-patients subgroup. They were clinically free and had normal FSH $(4.9 \mathrm{mIU} / \mathrm{mL} \pm 1)$. Their other hormones and lab data were normal.

\section{Sperm parameters}

All the study patients presented normal semen volumes (2.87 $\mathrm{mL} \pm 1.26)$. They showed abnormalities in their semen reports. These abnormalities involved one or more of the studied sperm parameter(s). The number of the patients presented with 2 combined abnormal parameters was higher than those of the patients who had either 1 or 3 abnormal parameters (Table 1 ).

The most frequently affected parameter was morphology (Table 2).
Abnormal sperm morphology in the CASA-patients subgroup This was seen involving the head, mid-piece and tail. The head was the part with the highest percentage of abnormalities $(40 \% \pm 4.4)$ compared with mid-piece $(24.3 \% \pm 6.5)$ or tail $(29.3 \% \pm 4.3)$. The most frequent head deformity was abnormal acrosome $(49.2 \% \pm 6.2)$. The controls showed significantly less anomalies in the sperm head $(21.6 \% \pm 5.2 ; \mathrm{p}<0.001)$ and acrosome $(20.1 \% \pm 3.5 ; \mathrm{p}<0.001)$.

\section{Relation between FSH level and semen parameters}

The level of FSH declined as the number of affected sperm parameters increased. However, this decline in FSH level was not significant (Table 1).

It was of interest that the FSH levels were obviously lower in all the patients' groups with abnormal sperm parameters compared to those levels of the patients' groups with normal parameters (Table 2).

Again, these differences in FSH levels were insignificant; except with total sperm motility. There were also no significant correlation between FSH level and semen volume $(\mathrm{r}=-0.27, \mathrm{p}=0.16)$ or any abnormally affected sperm parameter (Table 3).

No negative impact of smoking on the study variables No statistically significant differences were appreciated between the smoking and nonsmoking group in regard to any of the study variables (Table 4).

Table 1.

Categorization of FSH levels in relation to the number of negative sperm parameter(s)*.

\begin{tabular}{|ccc|}
\hline $\begin{array}{c}\text { Number of negative } \\
\text { sperm parameter(s) }\end{array}$ & $\begin{array}{c}\text { Patient number } \\
\text { (\%) }\end{array}$ & $\begin{array}{c}\text { FSH (mean } \mathbf{~ S D )} \\
\text { mlU/mL }\end{array}$ \\
\hline 1 & $5(17.2)$ & $1.22 \pm 0.29$ \\
\hline 2 & $14(48.3)$ & $1.17 \pm 0.20$ \\
\hline 3 & $10(34.5)$ & $1.07 \pm 0.20$ \\
\hline
\end{tabular}

Table 2.

Normal and abnormal sperm parameters of the study patients and FSH levels ( $\mathrm{mIU} / \mathrm{mL})$ in each group*.

\begin{tabular}{|c|c|c|c|c|c|c|c|}
\hline \multirow[t]{2}{*}{ Sperm parameter } & \multicolumn{3}{|c|}{ Normal levels } & \multicolumn{3}{|c|}{ Abnormal levels } & \multirow[t]{2}{*}{ p-value } \\
\hline & Mean \pm SD & $\begin{array}{l}\text { Patient no. } \\
\text { no. (\%) }\end{array}$ & $\begin{array}{c}\text { FSH } \\
\text { (mean } \pm \text { SD) }\end{array}$ & Mean \pm SD & $\begin{array}{c}\text { Patient no. } \\
\text { (\%) }\end{array}$ & $\begin{array}{c}\text { FSH } \\
(\text { mean } \pm \text { SD) }\end{array}$ & \\
\hline Count $\left(10^{6} / \mathrm{mL}\right)$ & $82.91 \pm 40.46$ & $11(38)$ & $1.16 \pm 0.28$ & $2.59 \pm 3.3$ & $18(62)$ & $1.14 \pm 0.18$ & 0.845 \\
\hline Total motility (\%) & $54 \pm 4.6$ & $11(38)$ & $1.27 \pm 0.13$ & $23.42 \pm 14.82$ & $18(62)$ & $1.08 \pm 0.23$ & 0.011 \\
\hline Active motility (\%) & $33.75 \pm 7.44$ & $8(27.6)$ & $1.17 \pm 0.14$ & $6.76 \pm 7.36$ & $21(72.4)$ & $1.14 \pm 0.25$ & 0.683 \\
\hline $\begin{array}{c}\text { Morphology (\%) } \\
\text { - WHO } 1992 \\
\text { - WHO } 1999\end{array}$ & $\begin{array}{c}37.5 \pm 9.6 \\
-\end{array}$ & $\begin{array}{c}4(13.8) \\
-\end{array}$ & $1.18 \pm 0.32$ & $\begin{array}{c}15.67 \pm 6.73 \\
6.39 \pm 1.33\end{array}$ & $\begin{array}{l}12(41.4) \\
\frac{13(44.8)}{25(86.2)}\end{array}$ & $\begin{array}{l}1.15 \pm 0.25 \\
1.13 \pm 0.18\end{array}$ & $\begin{array}{c}0.878 \\
-\end{array}$ \\
\hline
\end{tabular}

* Independent-samples T- test. 
Table 3.

Sperm parameters of the 29 study patients and correlation with FSH levels *.

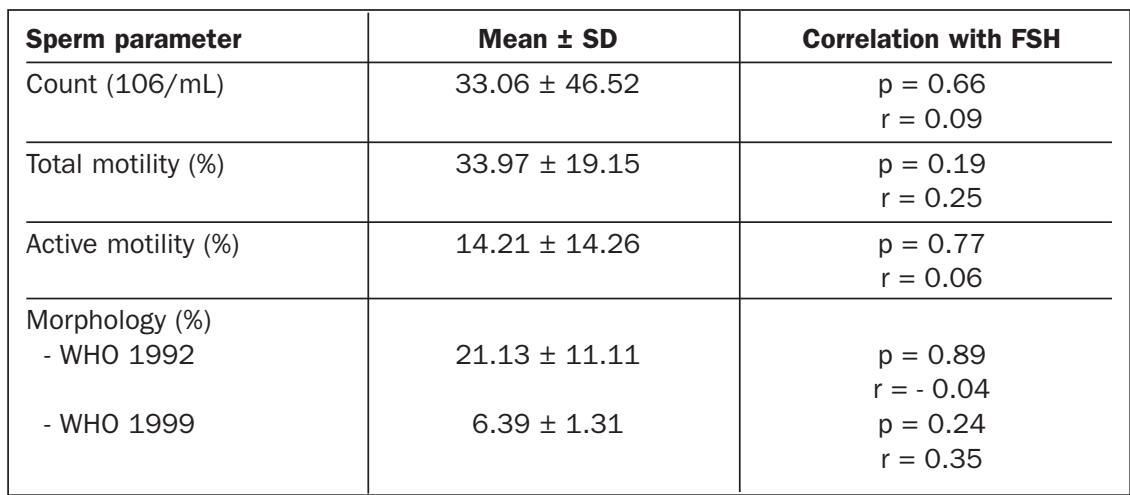

* Spearman rank correlation coefficient.

Table 4.

FSH levels and sperm parameters in relation to smoking *.

\begin{tabular}{|l|c|c|c|}
\hline Study point & Smoking group & Nonsmoking group & $\boldsymbol{p}$-value \\
\hline FSH level $(\mathrm{mIU} / \mathrm{mL})$ & $1.12 \pm 0.24$ & $1.14 \pm 0.19$ & 0.758 \\
\hline Semen volume $(\mathrm{mL})$ & $2.89 \pm 0.83$ & $2.59 \pm 0.74$ & 0.352 \\
\hline Sperm count $\left(10^{6} / \mathrm{mL}\right)$ & $43.61 \pm 57.19$ & $19.52 \pm 32.7$ & 0.2 \\
\hline Sperm total motility $(\%)$ & $36.15 \pm 18.61$ & $33.08 \pm 20.67$ & 0.694 \\
\hline Sperm active motility $(\%)$ & $14.77 \pm 12.94$ & $16.92 \pm 15.75$ & 0.707 \\
\hline Sperm normal forms $(\%)$ & $23.29 \pm 9.34$ & $18.33 \pm 17.22$ & 0.548 \\
- WHO 1992 & $6.67 \pm 1.63$ & $6.14 \pm 1.07$ & 0.52 \\
- WHO 1999 & & & \\
\hline
\end{tabular}

* Independent-samples T- test.

\section{Discussion}

Gonadotropin deficiency in men is rather uncommon. Low FSH was reported previously; either in studies dealing with hypogonadotrophic hypogonadism $(9,27)$ or without any note about other reproductive hormones (28). So, such reported low FSH was not an isolated deficiency. Recently, a study by Efesoy et al. (20) included a subgroup of infertile men with a real isolated low FSH among its other subgroups while checking for response to FSH therapy. However, the sample was very small in number and just touched at a glance without detailed reporting of related demographical, clinical or laboratory findings. Clinical studies investigating the isolated deficiency of FSH in males are lacking and mostly old case-reports $(17-19,29)$. Enrollment of male patients to launch a study related to this isolated hormonal deficiency, either clinically or epidemiologically, is extremely difficult. Therefore, the characteristic features of patients with this deficiency have not been well defined so far. In the present study out of 3335 infertile males, only 29 patients with isolated FSH deficiency were successfully recruited giving a prevalence of $0.87 \%$. To the best of our knowledge, this is the first study documenting this prevalence of isolated low FSH in infertile males, and it included the largest number of infertile men with this deficiency so far in the literature. This rarity of selec- tive FSH deficiency in males made some investigators to claim that existence of this deficiency as a primary entity is not clear (29).

These investigators presented case reports for patients with remarkably low and sometimes undetectable levels of FSH. In the current study, we presented a complete and true degree of selective FSH deficiency, and we think that it could be found as a primary entity. Three reasons may support our suggestion. First, the levels of FSH $(1.146 \pm 0.219 \mathrm{mIU} / \mathrm{mL})$ in our patients were obviously below the lower limit of normal laboratory range. This low level, a) was not due to spurious laboratory results as retesting FSH level confirmed the first result, and b) would remain low even on considering FSH periodicity which was documented in some studies to have an amplitude of $0.21 \pm 0.03 \mathrm{mIU} / \mathrm{mL}$ (30). The standardized chemiluminescence used in the present study was, therefore, suitable although it is less sensitive than other assays like Delfia method (31).

We wished also to test serum inhibin and anti-Mullerian hormone levels which could have been used as a lab corollary to the low FSH but such testing was, unfortunately, not available in this country during the time when the study patients were first seen in the clinic, long years ago. Second, we selected only the patients with really isolated low FSH. So, the potentially negative implications imposed by clinical or other reproductive hormonal disorders were excluded from the start. Third, tobacco smoking, which was the only unavoidable factor in the current study, did not cause any further adverse effect on the already declined sperm parameters. However the declined parameters of the patients in the smoking group showed less drop than those of the non-smoking group patients. This current finding about lack of negative effect of tobacco smoking comes in line with other investigators who denied any effect of smoking on any sperm parameter (32) but it disagrees with others who reported negative implications on sperm parameters induced by smoking (33).

This point may be criticized by some as the number of patients in the smoking group was 13 patients and might by relatively small to draw conclusion. However, recruitment of sufficient number of patients with isolated low FSH and also with negative history of smoking would be extremely difficult; if not impossible. We tried, in the present study, to exclude any factors with negative impact on sperm parameters as much as possible in order to demonstrate clearly the real relationship between isolated low FSH and sperm parameters. 
Pathogenic alterations in the hypothalamus or the pituitary have been incriminated as possible reasons for the defect in FSH secretion. In the current study, LH was within normal levels in all patients. So, a discrepancy in the levels of both hormones happened although different studies pointed out that both hormones are released from the same pituitary cell type (34). A possible explanation could be attributed to a change in the nature of GnRH pulse frequency and/or amplitude with a consequent abnormal FSH secretion by the pituitary cells (35). In support for this suggestion, recent studies demonstrated the differential interpretation ability of the same gonadotropin to the different GnRH inputs which depends mainly on signal-regulated mechanisms (36) as well as epigenetic factors (37) in maintaining these energetic responses of the gonadotropin.

Other causes which may decrease the FSH level alone may be attributed to multifaceted mutations in the coding region of the FSH gene (21). In the current study, screening for FSH- $\beta$ gene has not been done due to financial reasons. These shortcomings in the present study may not unveil the exact reasons involved in the isolated FSH decline in the study patients. The present study is just a preliminary report, and we are starting now to collect new patients with similar abnormality who will be thoroughly screened for possible etiology in a new study.

In the present work, isolated low FSH was associated with low percentage motile sperm in the majority of the patients. This comes in line with Efesoy et al. (20) and Novero et al. (28) although the number of patients in both studies were very limited. Maroulis et al. have also reported similar abnormalities in sperm motility in their case reporting for 2 patients (18). This drop in sperm motility may be explained on the basis of the alteration in Sertoli cell function due to the decline in FSH level which is known to stimulate its structure and function (3). This modification in function is expected to affect the growth factors secreted by the Sertoli cell (38) where many of these factors are known to promote sperm motility (39). Recent studies have addressed the existence of specific receptors for many of these factors on the sperm membrane itself (40).

This may be a probable reason why some patients of the current work were infertile although they had sufficient number of motile sperms which may deal with their problem of asthenospermia. The drop in sperm concentration in the majority (62\%) of the study patients is well accredited to the crucial role of FSH in the induction, regulation and maintenance of the spermatogenesis (3). The present study revealed also increased percentage abnormal forms as governed by WHO criteria $(24,25)$ in all patients, except only 4 . This ranked the abnormal sperm morphology as the most prevailing anomaly associated with isolated low FSH. We agree, therefore, with Novero and his co-workers (28) who showed a decline in normal forms in one of their patients and a borderline state in the second. The present study showed also an interesting finding, that is related to the sperm head anomalies. These anomalies represented the most frequent abnormalities in sperm morphology. They involved, in particular, the sperm acrosome. This may agree indirectly with Bartoov et al. (41) who showed that abnormal forms, from infertile men who were kept on FSH therapy, were associated with significant improvement in acrosome shape with drop in its agenesis to reach normal frequency.

The present finding of increased percentage of acrosome anomalies agrees also with Courtens and Courot (42) who showed that morphogenesis of the acrosome and its expansion in hypophysectomized ram was modulated by FSH and testosterone. Recently, the enhancing effect of recombinant FSH on sperm morphology was also addressed in many studies which reported a significant increase in the sperm normal morphology after treatment $(4,6-8,11,14,43)$. Some of these studies indicated clearly the drop in head and acrosomal aberrations with this treatment $(4,11)$.

\section{Conclusion}

Isolated low FSH in infertile men has a low prevalence. Disturbance in one or more sperm parameter (s) is (are) usually existent although abnormal sperm morphology was almost always present. Anomalous sperm head with abnormal acrosome were the most eminent morphological findings.

Therefore, the need to measure serum FSH concentration in the infertile male has been reconfirmed. Although the number of reported male patients with isolated low FSH in the literature is extremely limited so far, nevertheless, we believe that infertile men with isolated low FSH may be found as a primary entity in male infertility. Extension of this work to thoroughly screen these patients for possible etiologies is highly recommended to validate this hypothesis.

\section{Notes}

A master table containing the retrieved data of this study is documented, certified and saved at the Department of Urology, Alexandria Faculty of Medicine, Alexandria, Egypt.

\section{Statement of authorship}

Nader Salama: Conception and design of the study, collection, analysis and interpretation of data, and drafting the article with final approval of its completed form.

Mohamed El-Sawy: Collection and interpretation of the data, and drafting the article with final approval of its completed form.

\section{References}

1. Matsumoto AM, Karpas AE, Bremner WJ. Chronic human chorionic gonadotropin administration in normal men: evidence that follicle stimulating hormone is necessary for the maintenance of quantitatively normal spermatogenesis in man. J Clin Endocrinol Metab. 1986; 62:1184.

2. Foresta C, Betella A, Ferlin A, et al. Evidence for a stimulatory role of follicle-stimulating hormone on the spermatogonial population in adult males. Fertil Steril. 1998; 69:636.

3. Moyle WR. Gonadotropins. In: DeGroot LJ (Ed), Endocrinology. Philadelphia: WB Saunders. 2001; 1895. 
4. Ben-Rafael Z, Farhi J, Feldberg D, et al. Follicle-stimulating hormone treatment for men with idiopathic oligoteratoasthenozoospermia before in vitro fertilization: the impact on sperm microstructure and fertilization potential. Fertil Steril. 2000; 73:24.

5. Farmakiotis D, Farmakis C, Rousso D, et al. The beneficial effects of toremifene administration on the hypothalamic-pituitary-testicular axis and sperm parameters in men with idiopathic oligozoospermia. Fertil Steril. 2007; 88:847.

6. Foresta C, Bettella A, Garolla A, et al. Treatment of male idiopathic infertility with recombinant human follicle-stimulating hormone: a prospective, controlled, randomized clinical study. Fertil Steril. 2005; 84:654.

7. Foresta C, Selice R, Moretti A, et al. Gonadotropin administration after gonadotropin-releasing-hormone agonist: a therapeutic option in severe testiculopathies. Fertil Steril. 2009; 92:1326.

8. Foresta C, Betella A, Merico M, et al. Use of recombinant human follicle-stimulating hormone in the treatment of male factor infertility. Fertil Steril. 2002; 77:238.

9. Bakircioglu ME, Erden HF, Ciray HN, et al. Gonadotrophin therapy in combination with ICSI in men with hypogonadotrophic hypogonadism. Reprod Biomed Online. 2007; 15:156.

10. Selman H, De Santo M, Sterzik K, et al. Rescue of spermatogenesis arrest in azoospermic men after long-term gonadotropin treatment. Fertil Steril. 2006; 86:466.

11. Baccetti B, Piombon P, Bruni E, et al. Effect of follicle stimulating hormone on sperm quality and pregnancy rate. Asian J Androl. 2004; 6:133.

12. Arnaldi G, Balercia G, Barbatelli G, Mantero F. Effects of longterm treatment with human pure follicle-stimulating hormone on semen parameters and sperm-cell ultrastructure in idiopathic oligoteratoasthenozoospermia. Andrologia. 2000; 32:155.

13. Ashkenazi J, Bar-Hava I, Farhi J, et al. The role of purified follicle stimulating hormone therapy in the male partner before intracytoplasmic sperm injection. Fertil Steril. 1999; 72:670.

14. Caroppo E, Niederberger C, Vizziello GM, D’Amato G. Recombinant human follicle-stimulating hormone as a pretreatment for idiopathic oligoasthenoteratozoospermic patients undergoing intracytoplasmic sperm injection. Fertil Steril. 2003; 80:1398.

15. Silber SL, Van Steirteghem AC, Liu J, et al. High fertilization and pregnancy rates from intracytoplasmic sperm injection using spermatozoa obtained from testicle biopsy. Hum Reprod. 1995; 10:148.

16. Boitrelle F, Robin G, Marcelli F, et al. A predictive score for testicular sperm extraction quality and surgical ICSI outcome in nonobstructive azoospermia: a retrospective study. Hum Reprod. 2011; 26:3215.

17. Hagg E, Tollin C, Bergman B. Isolated FSH deficiency in a male: a case report. Scand J Urol Nephrol 1978; 12:287.

18. Maroulis GB, Parlow AF, Marshall JR. Isolated follicle-stimulating hormone deficiency in man. Fertil Steril. 1977; 28:818.

19. Diez JJ, Iglesias P, Sastre J, et al. Isolated deficiency of folliclestimulating hormone in man: a case report and literature review. Int J Fertil Menopausal Stud. 1994; 39:26.

20. Efesoy O, Selahittin C, Akbay E, et al. The efficacy of recombinant human follicle-stimulating hormone in the treatment of various types of male-factor infertility at a single university hospital. J Androl. 2009; 30:679.
21. Achermann JC, Weiss J, Lee EJ, et al. Inherited disorders of the gonadotropin hormones. Mol Cell Endocrinol. 2001; 179:89.

22. Rabinowitz D, Benveniste R, Lindner J, et al. Isolated follicle stimulating hormone deficiency revisited. Ovulation and conception in presence of circulating antibody to follicle-stimulating hormone. N Engl J Med. 1979; 300:126.

23. Haller K, Salumets A, Grigorova M, et al. Putative predictors of antibodies against follicle-stimulating hormone in female infertility: a study based on in vitro fertilization patients. Am J Reprod Immunol. 2007; 57:193.

24. WHO Laboratory Manual for the Examination of Human Semen and Sperm-Cervical Mucus Interaction. 3 ed. Cambridge: Cambridge University Press, 1992.

25. WHO Laboratory Manual for the Examination of Human Semen and Sperm-Cervical Mucus Interaction. 4 ed. Cambridge: Cambridge University Press, 1999.

26. Wang AW, Politch J, Anderson D. Leukocytospermia in male infertility patients in China. Andrologia. 1994; 26:167.

27. Liu PY, Turner L, Rushford D, et al. Efficacy and safety of recombinant human follicle stimulating hormone (Gonal-F) with urinary human chorionic gonadotrophin for induction of spermatogenesis and fertility in gonadotrophin-deficient men. Hum Reprod. 1999; 14: 1540 .

28. Novero V, Camus M, Tournaye H, et al. Relationship between serum follicle stimulating hormone in the male and standard sperm parameters, and the results of intracytoplasmic sperm injection. Hum Reprod. 1997; 12:59.

29. Mozaffarian GA, Higley M, Paulsen CA. Clinical studies in an adult male patient with "Isolated Follicle Stimulating Hormone (FSH) Deficiency”. J Androl. 1983; 4:393.

30. Walton MJ, Anderson RA, Kicmant AT, et al. A diurnal variation in testicular hormone production is maintained following gonadotrophin suppression in normal men. J Endocrinol. 2007; 66:123.

31. Robertson DM, Pruysers E, Stephenson T, et al. Sensitive LH and FSH assays for monitoring low serum levels in men undergoing steroidal contraception. Clin Endocrinol (Oxf). 2001; 55:331.

32. Shen HM, Chia SE, Ni ZY, et al. Detection of oxidative DNA damage in human sperm and the association with cigarette smoking. Reprod Toxicol. 1997; 11:675.

33. Kunzle R, Mueller MD, Hanggi W, et al. Semen quality of male smokers and nonsmokers in infertile couples. Fertil Steril. 2003; 79:287.

34. Phifer RF, Midgley AR, Spicer SS. Immunohistologic and histologic evidence that follicle-stimulating hormone and luteinizing hormone are present in the same cell type in the human pars distalis. $J$ Clin Endocrinol Metab. 1973; 36:125.

35. Ferris HA, Shupnik MA. Mechanisms for pulsatile regulation of the gonadotropin subunit genes by GNRH1. Biol Reprod. 2006; 74:993.

36. Burger LL, Haisenleder DJ, Dalkin AC, et al. Regulation of gonadotropin subunit gene transcription. J Mol Endocrinol. 2004; 33:559.

37. Melamed P. Histone deacetylases and repression of the gonadotropin genes. Trends Endocrinol Metab. 2008; 19:25.

38. Mruk D, Yan-Cheng C. Sertoli-sertoli and sertoli-germ cell interactions and their significance in germ cell movement in the sem- 
iniferrous epithelium during spermatogenesis. Endocr Rev. 2004; 25:747.

39. Hermo L, Oko R, Morales C. Secretion and endocytosis in the male reproductive tract: a role in sperm maturation. Int Rev Cytol. 1994; 154:105.

40. Naz RK, Sellamuthu R. Receptors in spermatozoa: are they real ? J Androl. 2006; 27:627.

41. Bartoov B, Eltes F, Lunenfeld E, et al. Sperm quality of subfer- tile males before and after treatment with human follicle-stimulating hormone. Fertil Steril. 1994; 61:727.

42. Courtens JL, Courot M. Acrosomal and nuclear morphogenesis in ram spermatids: an experimental study of hypophysectomized and testosterone-supplemented animals. Anat Rec. 1980; 197:143.

43. Selice R, Garolla A, Pengo M, et al. The response to FSH treatment in oligozoospermic men depends on FSH receptor gene polymorphisms. Int J Androl. 2011; 34:306.

\section{Correspondence}

Nader Salama, MD (Corresponding Author)

Department of Urology

Alexandria Faculty of Medicine

Alexandria, EGYPT

nadersalama58@yahoo.com

Mohamed El-Sawy, MD

Department of Clinical Pathology

Alexandria Faculty of Medicine

Alexandria, EGYPT

elsawymohamed@gmail.com 